\title{
Effectiveness of Injectable Artesunate Versus Quinine in The Treatment of Severe Malaria in Children Aged 0-59 Months in Kenge, DRC
}

\author{
Prisca Nsimba Mayamba ${ }^{1 *}$, Joel Kafumbi Katsiatsia ${ }^{1}$, Cush Ngonzo Luwesi ${ }^{2}$, Jean-Jacques Kisaka \\ Ngimbi $^{1,3}$ and Gertrude Lundu Yenamawu ${ }^{1}$ \\ ${ }^{1}$ Assistant Higher Institute of Medical Techniques Mary Queen of Peace Kenge (ISTM-MRP), Kenge, DRC \\ ${ }^{2}$ Associate Professor, Faculty of Economics, University Kwango (UNIK), Kenge, DRC \\ 3Executive Secretary, Civil Society Health Kwango, Kenge, DRC
}

*Corresponding author: Prisca Nsimba Mayamba, Assistant Higher Institute of Medical Techniques Mary Queen of Peace Kenge (ISTM-MRP), Kenge, DRC

\section{ARTICLE INFO}

Received: 蔧 May 20, 2019

Published: May 29, 2019

Citation: Prisca Nsimba M, Joel Kafumbi K1, Cush Ngonzo L, Jean-Jacques Kisaka $\mathrm{N}$, Gertrude Lundu Y. Effectiveness of Injectable Artesunate Versus Quinine in The Treatment of Severe Malaria in Children Aged 0-59 Months in Kenge, DRC. Biomed J Sci \& Tech Res 18(3)-2019. BJSTR. MS.ID.003155.
ABSTRACT

Malaria Threatens globally the lives of 3.3 trillion people living in 109 countries. This study compares the effectiveness avocation to of the drug artesunate versus quinine That of in the treatment of severe malaria Among the children of less than 59 months. For That reason, a survey and quantitative cross-sectional analysis has documentary Were Conducted one year based design to suit les explanatory correlation has entre les drugs and the rate of malaria treatment. A sample size of 380 children Was selected from the City of Kenge, half of Whom Were Treated with artesunate (190 children) and the other half with quinine (190 children). Results indicate indication at 5\% significance level That $59 \%$ of patients Treated with artesunate drug Had a drop in temperature During the first day of treatment contre $49.5 \%$ Treated with drug quinine. The cure rate Was Observed $88.9 \%$ for the artesunate group versus $83.7 \%$ for the quinine group. The death rate Was Established at 7.9\% for the quinine group contre $1.1 \%$ for the artesunate group. Finally, a correlation Was Established entre les kind of treatment, parasitaemia at the start of the treatment, the adjuvant treatment, the Evolution of clinical signs During treatment, the final assessment, and the treatment effectiveness.

Hence, the artesunate Was found to be more effective than quinine in Treating severe malaria. the final assessment, and the treatment effectiveness. Hence, the artesunate Was found to be more effective than quinine in Treating severe malaria. the final assessment, and the treatment effectiveness. Hence, the artesunate Was found to be more effective than quinine in Treating severe malaria.

\section{Summary}

Malaria threatens 3.3 billion people in 109 countries in the world. This study aimed to compare the effectiveness of artesunate versus quinine in the treatment of severe malaria in children aged 0-59 months. We conducted a cross-quantitative investigation; correlational explanatory quote based on the literature review. A sample of 380 children was selected in the City of Kenge, of which 190 treated with artesunate and half treated with quinine. The results indicate a $5 \%$ significance level of $59 \%$ of patients treated with artesunate experienced a temperature drop on the first day against $49.5 \%$ treated with quinine. Moreover, the cure rate was $88.9 \%$ observed in the group of artesunate against $83.7 \%$ in the group of quinine. The death rate it was $7.9 \%$ in the group of quinine against $1.1 \%$ in the group of artesunate. Finally, interdependence were established between the established treatment parasitaemia at the beginning of treatment, adjuvant treatment, the evolution of clinical symptoms during treatment, the final evaluation and treatment efficacy. In conclusion, artesunate was more effective than quinine on the treatment of severe malaria or severe malaria. 


\section{Introduction}

Malaria is a major public health problem that threatens 3.3 billion people in 109 countries around the world, especially in SubSaharan Africa, with high mortality, in the order of 1 death every 30 seconds in children under 5 years old. Its socio-economic impact is in the billions of dollars [1]. While the entire population seems to be at risk of infection, children under 5 years and pregnant women are the most affected [2]. In the Democratic Republic of Congo (DRC), malaria is a major public health problem. It is the leading cause of morbidity and mortality especially among children under five and pregnant women. This disease killed 467,000 people, including 200,000 children aged 0-59 months, according to figures released by the Ministry of Health in 2000 with an average of 500,000 deaths per year [3]. Different observations of cases of treatment failure or even resistance to oral malaria were recorded in Kenge in the area of health, provincial health division Kwango. Indeed, 6 out of 1,530 cases $(0.39 \%)$ were recorded in 2015 , and 5 in 1,365 cases $(0.36 \%)$ registered in 2016 in the health center Holy Spirit; 4 of 832 cases $(0.48 \%)$ recorded in 2015, and 5 of 965 cases $(0.51 \%)$ recorded in 2016 at the health center CBCO [4].

The World Health Organization (WHO) recommends from 2014 introduction of injectable artesunate molecule in the first line treatment of severe malaria instead of quinine infusion [3]. This recommendation is widely applied in health facilities Kwango in general and Kenge Reference General Hospital in particular. Despite this use, or health facilities, even less recipients patients were interested to verify the therapeutic response between these two molecules. What justifies this comparative study on the effectiveness between injectable artesunate, a molecule of choice following the national protocol, and quinine, a molecule that is still more effective in treatment of malaria. The study set out to answer the following questions: what is the therapeutic efficacy of artesunate compared with parenteral quinine in children under 5 years with severe malaria? What are the factors related to the effectiveness of injectable artesunate versus quinine in the treatment of severe malaria in children less than 59 months?

Thus the primary objective of this study was to compare the efficacy of injectable artesunate than quinine in the treatment of severe malaria in children younger than 59 months treated Kenge Reference General Hospital. The study was specifically designed to

(i) determine the clinical and parasitological efficacy of injectable artesunate versus quinine in the treatment of severe malaria in children under 5

(ii) Identify the factors of the effectiveness of injectable artesunate and quinine in patients supported severe malaria.

\section{Literature paper}

Malaria treatment still pose serious difficulties. Several classes of products have successively emerged, each with its advantages and disadvantages, but the range of drugs remains narrow for the discovery of new malaria seems laborious [5]. Despite these advances in malaria surveillance and treatment availability, some people worry that it will take to adopt "radical measures" to curb forms of malaria resistant to drugs and prevent that history has proven to be intercontinental deadly spread [6]. Antimalarial drug resistance is a real public health impact. Individually, treatment failures it generates increase malaria mortality [7]. Moreover, the persistence of parasites in the blood increases the risk of severe anemia and consequently the frequency of blood transfusions with all the risks that entails. Collectively, the resistors increase the level of malaria transmission, which raises the number of accesses and therefore the cost of consultations per patient. The development of resistance of Plasmodium falciparum to amino-4-quinoléites and its rapid spread throughout the malarious areas of the world quickly revealed the need to consolidate the policies against malaria. The distribution of known resistance to other antimalarial drugs and decreased sensitivity to quinine has prompted the development of new molecules with antimalarial activity. The development of these antimalarial substances was based on extensive studies of traditional pharmacopoeia [8].

Experts from Public Health and scientists fear that the third wave of resistance to antimalarial history spreads in Asia and Africa if "radical measures" are not adopted quickly. The presence of strains resistant to artemisinin on Thailand-Cambodia border threatens indeed the effectiveness of treatment and poses challenges regarding the containment of the disease. Resistance has also been associated with the use of counterfeit drugs, poor quality or unregulated migration and unusual genetic structure of malaria parasites found in western Cambodia [6]. At present, the resistance thresholds in several major antimalarials (quinine, amodiaquine, artemisinin, mefloquine, lumefantrine) remain undefined. Quinine is still today the standard treatment for severe malaria falciparum worldwide [9]. If one is striving to recommendations WHO (2014), One can readily say that the effectiveness of the injectable artemisinin would be higher than quinine in terms of the treatment of severe malaria. Factors related to patients' behavior such as the observance of medical prescriptions, self-medication, factors related to pests and factors related to drugs would influence the effectiveness of injectable artesunate and quinine in the care of children under 5 years old.

\section{Materials and Methods}

\section{Description of the Study Environment}

Our study is the middle of the General Hospital of Catholic Conventionné Reference (HGRCC) Kenge 1. The history of this hospital back of state clinic created in 1958 for the Aboriginal population. In January 1960, the Director Mr. Christmas Kikwa completed the construction of the building that housed the Internal Medicine and Pediatrics. The clinic functioned initially after independence, in the building that now houses the Central Board of Health Area Rural Kenge (BCZS), while the Maternity in 
the pavilion where the current pavilion surgery. In 1988, a contract will be signed between the German Government on the one hand and the Congo on the other hand, the Diocese of Kenge included. At the beginning, the project will rehabilitate the clinic and creates the Rural Health Zone with Hospital Kenge 1 as the General Referral Hospital. The Kenge HGRCC of 1 is located on the Avenue Clinic in the city of Kenge 1 Capital of Territory Administration Kenge 1, in the area of Rural Health Kenge, Kwango District, Bandundu Province, Democratic Republic of Congo (DRC). It is 275 km from Kinshasa, the entrance is $1.5 \mathrm{~km}$ of the national road No. 1 Kinshasa-Kikwit.

HGRCC The Kenge 1 provides a complementary package of activities as a hospital General Reference. It organizes curative, preventive and promotional. Its administrative structure includes a management committee, Team Framework Health Area Rural Kenge and Director of the Hospital Committee. The Congolese state has sold conventionally managing this hospital to the ASBL Diocese of Kenge. Technically, the Kenge 1 HGRCC support 92 agents including 6 Doctors, two Directors Managers, Nutritionists 3, 3 laboratory technicians and 3 Microscopists; 49 nurses including a Director of Nursing; 4 midwives, 7 and 9 ordinary workers Administrative staff. The healthcare team provides preventive, curative to achieve a good recovery of the health of patients or outpatients. Its capacity of 135 beds mounted.

\section{Sampling Method and Techniques Data Collection}

This study is based on data collected during a period from 01 January to 31 December 2016, after a cross quantitative survey correlational explanatory quotes and literature review. A probabilistic sample from simple random manner was used to select 380 children under 59 months out of a total population of 728 children hospitalized with HGRCC Kenge 1 due to severe malaria confirmed clinically and in the laboratory. Selection consisted of 190 treated with artesunate and 190 with injectable quinine. This equal distribution of $50 \%$ for artesunate and $50 \%$ by quinine was made for convenience, but the size of the sample was calculated according to the formula of Fischer.

Selection Criteria: Before including a child in the study sample, the researchers established the following criteria:

i. Being a child aged 0 to 59 months

ii. To be admitted to hospital or pediatric emergency for severe malaria, and

iii. Be under treatment artesunate or injectable quinine.

Exclusion Criteria: Was supposed to be excluded from the sample, all patients who received a treatment regimen other than quinine and artesunate or have been treated outside the period of the study.

Data Analysis Techniques: Analyzes were mainly descriptive based on the calculation of frequencies and statistical inferences. Descriptive analysis consisted of describing the strength of the sample by age and sex.
Trends were identified on the basis of Equation 1:

$$
f=\frac{F 0}{F A_{1}} * 100
$$

Or,

Relative frequency $\mathrm{f}=$

$\mathrm{FO}=$ Observed frequency

$\mathrm{FA}=$ expected frequency

The chi-square test (Chi2 or $\square^{2}$ ) has been used for compare different factors of clinical and parasitological efficacy between patients treated with injectable artesunate and those treated with quinine. This inferential analysis atallowed to test the null hypothesis that there was a significant difference between healing parameters expected in patients treated with injectable artesunate(E) and those observed patients treated with quinine injectable(0). Thus, the following assumptions were testedes:

a) H0: $\mathrm{E} \neq 0$, there is a significant difference between the distributions of $\mathrm{E}$ and $\mathrm{O}$

b) $\mathrm{H} 1$ : $\mathrm{E}=\mathrm{O}$, there is no significant difference between the $\mathrm{E}$ and $\mathrm{O}$ distributions

From an analytical point of view, the chi-square statistic (or Khi2 $\square^{2}$ ) Is represented by the formula next (Equation 2):

$$
\chi_{d d l ; p}^{2}=\sum \frac{\left(E_{j}-O_{i}\right)^{2}}{O_{i}}
$$

Où,

Ei,the expected strength of the Patients treated with injectable artesunate

Oj, th $^{\text {th }}$ the actual observed Patients treated with parenteral quinine

dOF, The degree of freedom (equal to nk)

not, The total strength of the sample

$\mathrm{k}$ The number of estimated parameters (equal to the number of factors)

pThe significance level (equal to the probability of failure of Ho)

The chi-square statistic (Khi2) was tested at the $5 \%$ significance level ( $p=0.05$ ) using the SPSS 12.0 software and MS Excel 2010.

\section{Analysis Results}

\section{Profile of The Surveyed Patients}

The results in Table 1 show that $45.3 \%$ of 190 patients registered in the group of quinine were younger than 11 months, $17.4 \%$ of 24 to 35 months, $15.8 \%$ of 12 to 23 months, $116 \% 36$ to 47 months, and $10 \%$ from 48 to 59 months. In the group of artesunate $43.2 \%$ of patients were younger than 11 months, $17.9 \%$ of 24 to 35 months; $15.8 \% 12$ to 23 months, $13.6 \%$ from 36 to 47 mois, and $10 \%$ from 48 to 59 months. Regarding the sex ratio, 112 patients out of 190 
treated with quinine $(59 \%)$ were male against 78 patients $(41.1 \%)$ female. The group of artesunate was dominated by 106 female patients of the 190 (55.8\%) against 84 patients (44.21\%) male Figure 1. It is apparent from Table 2 that in the parasitemia quinine group is characterized by a TDR much more positive (78.9\% of cases) followed by positive thick smear (GE +) (12.6\% of cases) and GE and
$\mathrm{TDR}+(4.2 \%)$. TDR negative and negative GE were not significant respectively 6 and 2 cases out of 190, representing 3.2\% and 1.1\%. From the group of artesunate, the parasitemia was characterized by positive GE ( $83.7 \%$ of cases) followed by the TDR positive $(8.4 \%)$ and the negative GE (7.9\%). No cases of TDR negative were recorded in patients treated with artesunate.

Table 1: Distribution of respondents by age.

\begin{tabular}{|c|c|c|c|c|}
\hline \multirow{2}{*}{ Age (Per Month) } & \multicolumn{2}{|c|}{ Quinine } & \multicolumn{2}{c|}{ Artesunate } \\
\cline { 2 - 5 } & Frequency & Percent & Frequency & 43.16 \\
\hline $0-11$ & 86 & 45.26 & 82 & 15.79 \\
\hline $12-23$ & 30 & 15.79 & 30 & 17.89 \\
\hline $24-35$ & 33 & 17.37 & 25 & 13.16 \\
\hline $36-47$ & 22 & 11,58 & 19 & 10.00 \\
\hline $48-59$ & 19 & 10.00 & 190 & 100.00 \\
\hline Total & 190 & 100.00 & & \\
\hline
\end{tabular}

Source : Authors (2017)

Table 2: Evaluation of parasitaemia patients on admission.

\begin{tabular}{|c|c|c|c|c|}
\hline \multirow{2}{*}{ Age (Per Month) } & \multicolumn{2}{|c|}{ Quinine } & \multicolumn{2}{c|}{ Artesunate } \\
\cline { 2 - 5 } & Frequency & Percent & Frequency & 83.7 \\
\hline GE + & 24 & 12.6 & 159 & 7.9 \\
\hline GE - & 2 & 1.1 & 16 & 8.4 \\
\hline TDR + & 150 & 78.9 & 0 & 0.0 \\
\hline TDR- & 6 & 3.2 & 0 & 0.0 \\
\hline GE and TDR + & 8 & 4.2 & 190 & 100.00 \\
\hline Total & 190 & 100.00 & & \\
\hline
\end{tabular}

Source : Authors (2017)

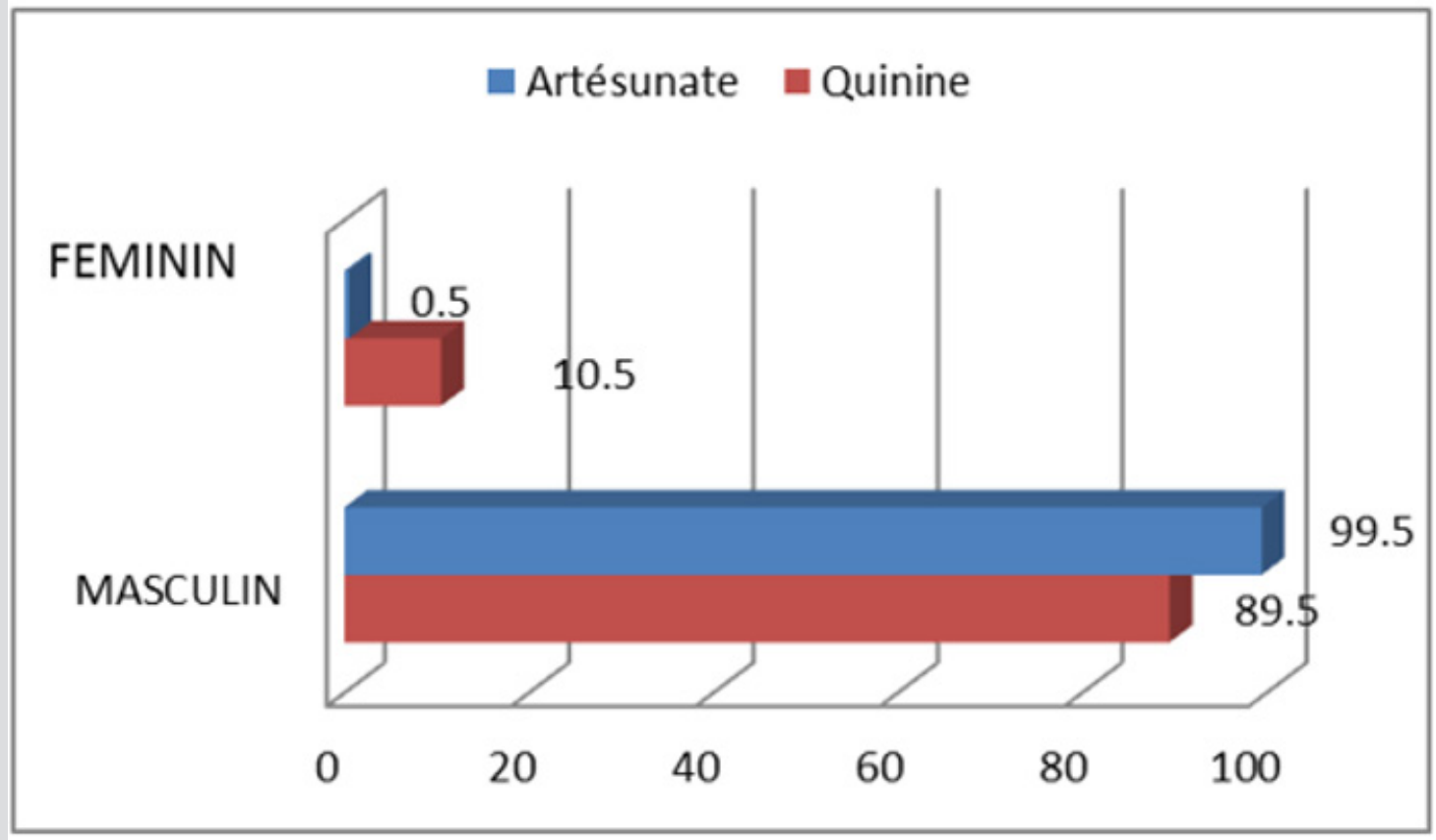

Figure 1: Distribution of respondents by sex (Authors, 2017). 


\section{Factors Related to Medication Taken by Patients}

Regarding the adjuvant, Table 3 indicates that respondents following treatment of quinine in combination with an antipyretic, an antibiotic and a transfusion accounted for 102 patients 190 (53.7\%) followed by those in which quinine was associated with a Antipyretic and an antibiotic (68 patients, 35.8\%).The associationQuinine with blood transfusion alone or Antibiotic only have respectively represented $7.9 \%$ (ie 15 cases) and $2.6 \%$ (equivalent to 5 cases). However in the group of artesunate, Antipyretic association, an antibiotic and transfusion was prescribed to 124 patients
190 (65.3\%), followed by the combination of a Antipyretic and an antibiotic (32 cases, 16.8\%), blood transfusion (6 cases, 3.2\%), association of an antibiotic (4 cases, 2.1\%) and combination of a Antipyretic (24 cases , 12.6\%). Regarding the evolution of clinical signs (esp. The temperature) in patients during treatment, Table 4 shows that 94 of 190 (49.5\%) of patients had suppression of sign in the first day the group of quinine, while this figure amounted to $59 \%$ (or 112 of 190 patients) in the group of artesunate. The suppression of clinical signs on day 51 was obtained from 190 patients on quinine (26.8\%), and 43 patients on artesunate (22.6\%).

Table 3: Distribution of the surveyed according adjuvant.

\begin{tabular}{|c|c|c|c|c|}
\hline \multirow{2}{*}{ Adjuvant Treatment } & \multicolumn{2}{|c|}{ Quinine } & \multicolumn{2}{|c|}{ Artesunate } \\
\hline & Frequency & Percent & Frequency & Percent \\
\hline Associating an antipyretic & 0 & 0.0 & 24 & 12.6 \\
\hline Association of antibiotic & 5 & 2.6 & 4 & 2.1 \\
\hline blood transfusion & 15 & 7.9 & 6 & 3.2 \\
\hline Antipyretic Association, antibiotic and transfusion & 102 & 53.7 & 124 & 65.3 \\
\hline Associating an antipyretic and antibiotic & 68 & 35.8 & 32 & 16.8 \\
\hline Total & 190 & 100.00 & 190 & 100.00 \\
\hline
\end{tabular}

Source : Authors (2017)

Table 4: Evolution of temperature in patients during treatment.

\begin{tabular}{|c|c|c|c|c|}
\hline \multirow{2}{*}{ Evolution Of Clinical Signs } & \multicolumn{2}{|c|}{ Quinine } & \multicolumn{2}{|c|}{ Artesunate } \\
\hline & Frequency & Percent & Frequency & Percent \\
\hline sign Suppression $1^{\text {st }}$ day & 94 & 49.47 & 112 & 58.95 \\
\hline sign Suppression $2^{\text {nd }}$ day & 51 & 26.84 & 43 & 22.63 \\
\hline sign Suppression $3^{\text {rd }}$ day & 21 & 11.05 & 28 & 14.74 \\
\hline Persistence signs the $4^{\text {th }}$ day & 24 & 12.63 & 7 & 3.68 \\
\hline Total & 190 & 100.00 & 190 & 100.00 \\
\hline
\end{tabular}

Source : Authors (2016)

On the third day, 21 patients in the first group (quinine) had the sign removal (11.1\%) and 28 patients in the second group (14.7\%). On the fourth day, there were 24 cases of persistence against quinine (12.6\%), while continuing to artesunate not represented that 7 cases (3.7\%). In terms of the final evolution, 159 patients in the quinine (or $83.7 \%$ ) were discharged from the hospital cured against 169 patients in the group of artesunate (88.9\%). There were 15 deaths out of 190 patients in the quinine (7.9\%) in group 2 against artesunate (1.1\%). However, there was more escaped in the group of artesunate (19 cases, 10.1\%) and less escaped in one of quinine ( 16 cases, $8.4 \%$ ). Table 5 summarizes these results. Finally, the effectiveness evaluation shows that the group of artesunate appears more effective (99.5\%) than that of quinine $(89.5 \%)$. Furthermore, the assessment of non-effectiveness revealed $0.5 \%$ inefficiency for the group of artesunate and $10.5 \%$ inefficiency for the group of quinine Figure 2. In conclusion, the administration of artesunate contribute more effectively and efficiently in the treatment of severe malaria or severe malaria.

Table 5: Final Treatment Evaluation.

\begin{tabular}{|c|c|c|c|c|}
\hline \multirow{2}{*}{ Final Evaluation } & \multicolumn{2}{|c|}{ Quinine } & \multicolumn{2}{c|}{ Artesunate } \\
\cline { 2 - 5 } & Frequency & Percent & Frequency & 169 \\
\hline recovered & 159 & 83.7 & 2 & 1.1 \\
\hline deceased & 15 & 7.9 & 19 & 10.1 \\
\hline Escaped & 16 & 10.4 & 190 & 100.00 \\
\hline Total & 190 & 100.00 & 190 \\
\hline
\end{tabular}




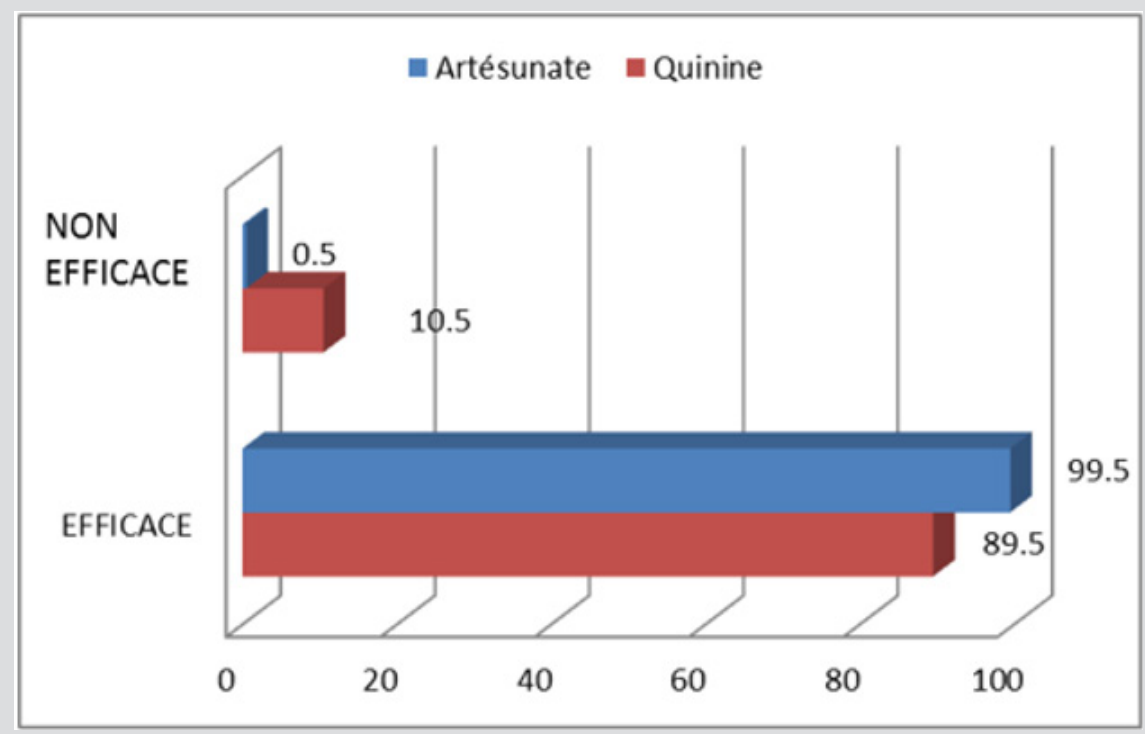

Figure 2: Analysis of efficacy after the treatment.

\section{Relationship Between Parasitaemia, Treatment and Drug Efficacy}

Interrogates the relevance of the relationship between measures of effectiveness of drugs used to treat malaria and type of treatment initiated, the test Chi Square has established a significant relationship of interdependence between the established treatment and the effectiveness of treatment 99\% confidence level (Chi-square $=17.11, \mathrm{df}=1 ; \mathrm{p}=0.00$ ) Table 6 . as to the relationship between molecules efficiency measures and parasitaemia at the beginning of the treatment, the Table7 establishesa significant influence of parasitaemia on the effectiveness of treatment with $99 \%$ confidence level (Chi-square $=22.65, \mathrm{df}=4, \mathrm{p}=0.00$ ). The test Chi Square also established statistically significant relationships between adjuvant and effectiveness of the treatment at 95\% confidence level (Chisquare $=9.50, \mathrm{df}=4, \mathrm{p}=0.05$ ) Table 8 . About the relationship between the evolution of clinical signs during the treatment of malaria (esp. Temperature) and the efficacy of the molecule, Table9 statistically significant relationships established at $95 \%$ confidence level between the evolution of the current temperature of treatment and the efficacy of treatment. (Chi-square $=10.29$, df $=3, p=0.02$ ). Finally, asked about the interdependence of the final assessment and the effectiveness of treatment, the test Chi Square has confirmeded the relevance of this statistical relationship $99 \%$ confidence level (Chi-square $=288.52, \mathrm{df}=2, \mathrm{p}=0.00$ ) Table 10 .

Table 6: Relationship between treatment initiated and the efficacy of the compound $1^{*}$.

\begin{tabular}{|c|c|c|c|c|}
\hline Treatment Initiated & Effective & Non-Effective & Total & $\mathbf{8 8 . 9}$ \\
\hline Quinine injection & 170 & 19 & 189 & 1.1 \\
\hline artesunate & 188 & 1 & 189 & 10.1 \\
\hline Total & 358 & 20 & 378 & 100.00 \\
\hline
\end{tabular}

Source : Authors (2017)
Notes: * Statistical inference based on the test Chi Square valued at $5 \%$ significance level.

Table 7: Relationship between parasitaemia admission and efficacy of the compound $1^{*}$.

\begin{tabular}{|c|c|c|c|}
\hline Parasitaemia At Admission & Effective & Non-Effective & Total \\
\hline GE + & 182 & 1 & 183 \\
\hline GE - & 17 & 0 & 17 \\
\hline TDR + & 146 & 19 & 165 \\
\hline TDR- & 6 & 0 & 6 \\
\hline GE AND TOR + & 7 & 0 & 7 \\
\hline Total & 358 & 20 & 378 \\
\hline
\end{tabular}

Source : Authors (2017)

Notes : * Statistical inference based on the test Chi Square valued at $5 \%$ significance level.

Table 8: Relationship between adjuvant therapy and treatment efficacy * 1 .

\begin{tabular}{|c|c|c|c|}
\hline $\begin{array}{c}\text { Adjuvant Treatment } \\
\text { Introduced }\end{array}$ & Effective & Not Effective & Total \\
\hline Antipyretic & 23 & 1 & 24 \\
\hline antibiotic + & 8 & 0 & 8 \\
\hline Blood transfusion & 16 & 4 & 20 \\
\hline $\begin{array}{c}\text { Antipyretic }+ \text { antibiotic }+ \\
\text { transfusion }\end{array}$ & 216 & 10 & 226 \\
\hline Antipyretic + antibiotic & 95 & 5 & 100 \\
\hline Total & 358 & 20 & 378 \\
\hline
\end{tabular}

Source : Authors (2017)

Notes: * * Statistical inference based on the test Chi Square valued at $5 \%$ significance level

1 Chi-square $=9.498$;

$\mathrm{ddl}=4$;

$\mathrm{p}=0.050$ 
Table 9: Relation between changes in clinical signs and treatment effectiveness *.

\begin{tabular}{|c|c|c|c|}
\hline Evolution Of The Temperature & Effective & Not Effective & Total \\
\hline sign Suppression Day 1 & 197 & 9 & 206 \\
\hline sign Suppression 2nd Day & 92 & 2 & 94 \\
\hline sign Suppression 3rd Day & 42 & 7 & 49 \\
\hline Persistence signs 4th Day & 27 & 2 & 29 \\
\hline Total & 358 & 20 & 378 \\
\hline
\end{tabular}

Source : Authors (2017)

Notes : * * Statistical inference based on the test Chi Square valued at $5 \%$ significance level

1 Chi-square $=10.287$;

$\mathrm{ddl}=3$;

$\mathrm{p}=0.016$

Table 10: Relationship between the final evaluation and treatment efficacy $1^{*}$.

\begin{tabular}{|c|c|c|c|}
\hline Final Evaluation & Effective & Not Effective & Total \\
\hline recovered & 326 & 0 & 326 \\
\hline deceased & 1 & 16 & 17 \\
\hline Escaped & 31 & 4 & 35 \\
\hline Total & 358 & 20 & 378 \\
\hline Total & 358 & 20 & 378 \\
\hline
\end{tabular}

Source : Authors (2017)

Notes: * Statistical inference based on the test Chi Square valued at $5 \%$ significance level

1 Chi-square = 288.517;

$\mathrm{ddl}=2$;

$\mathrm{p}=0.000$

\section{Discussion of Results}

\section{Discussion of The Therapeutic Efficacy of The Treatment of Severe Malaria}

The first objective of this study was to determine the therapeutic efficacy of artesunate vis-à-vis the quinine in the treatment of severe malaria in children under 5 years. Given the results, it should be noted that the therapeutic response of artesunate is more effective than quinine $99 \%$ confidence level (Chi-square $=17.11 \mathrm{df}$ $=1, p=0,00)$. And, several previous studies confirm these results, although conducted in different categories of the population, adults for each child for others and for purely different contexts, especially in Africa and Asia where the disease is endemic and rampant in all its forms, and in Europe or America. Nevertheless, these results converge almost all toward the same direction, confirming the superiority of artesunate with quinine in term of therapeutic response [8-10]. Moreover, the study also set out to compare different parameters clinical and biological to determine the effectiveness of each of the molecules. The evaluation of the time required for the drop-in temperature between different population groups revealed that $59 \%$ of patients on artesunate had already experienced a temperature returned to normal within 24 hours following treatment (against 49, 5\% of patients receiving quinine).

Persistent fever was observed until the fourth day for a minority of patients on artesunate $(3.7 \%)$ and $12.6 \%$ of those who were subjected to the treatment of quinine. Significant relationships were found between changes in clinical signs during treatment and treatment effectiveness (Chi-square $=10.29, \mathrm{df}=3, \mathrm{p}=0.02$ ). The assessment of the duration of the temperature drop is, indeed, one of the most important parameters to be considered for detecting the time required for a therapeutic response of the molecule. The study by Fargiere et al. (1999) on the trial of artemether and quinine in severe falciparum malaria in adults and older children in Cameroon has identified the average time for negativity of parasitaemia between 16 and 64 hours (with a confidence interval of $34.6 \pm 9.6$ ) in artemether and between 24 and 64 hours (with a confidence interval $42.4 \pm 9.7$ ) as quinine. The study notes a significant gain of 7.8 hours $(p=0.0004)$ in patients receiving artemether [11-13].

In his study on the efficacy of artemether versus that of quinine in the treatment of severe malaria in children in Rwanda Ndimubanzu (2003) found that after 38 hours (with a confidence interval of $1224 \pm 63.76$ ), $50 \%$ of patients taking artemether no longer have fever. For patients taking quinine this proportion is reached at the 48th hour (with a confidence interval 37.26 \pm 58.74). [14-16] These results are slightly lower than those found in our study. However, observing closely the different results, it should be concluded that injectable artesunate would be much faster than quinine so that within 24 hours already, Regarding the overall evolution of the patients, our study showed that $88.9 \%$ of patients receiving injectable artesunate were declared cured against $83.7 \%$ of patients on quinine. Similarly, the death rate was higher in the group of quinine $(7.9 \%)$ than in patients receiving injectable artesunate (1.1\%). The highly statistically significant relationships obtained between the final evaluation and treatment effectiveness (Chi-square $=288.52, \mathrm{df}=2, \mathrm{p}=0.00$ ) confirmed the superiority of artesunate versus quinine. These results confirm earlier studies by the High Council for Public Health (2013), which followed 1,461 patients (14\% children) with severe malaria.

The study demonstrated superiority of artesunate (AS) on quinine (Q) in terms of mortality ( $15 \%$ versus $22 \%, p=0.0002$ ) and tolerance (risk of hypoglycemia three times lower than in the group $\mathrm{Q} ; \mathrm{p}=0.009$ ). The study concluded that artesunate significantly improves patient survival, a finding that is consistent with a similar study conducted by Morch et al. These authors have found that the reduction of mortality in children treated with artesunate was significant for deaths beyond 24 hours after admission $(\mathrm{RR}=0.63$ [0.47 \pm 0.87$] \mathrm{p}=0.004$ ) but not for those occurring in the first 24 hours $(R R=0.84[0.67 \pm 1.04], p=0.109$ ). conclusion corroborates the latest study by Morch et al. These authors have found that the reduction of mortality in children treated with artesunate was significant for deaths beyond 24 hours after admission $(R R=0.63$ 
$[0.47 \pm 0.87] p=0.004$ ) but not for those occurring in the first 24 hours $(R R=0.84[0.67 \pm 1.04], p=0.109)$. conclusion corroborates the latest study by Morch et al. These authors have found that the reduction of mortality in children treated with artesunate was significant for deaths beyond 24 hours after admission $(R R=0.63$ $[0.47 \pm 0.87] \mathrm{p}=0.004$ ) but not for those occurring in the first 24 hours $(\mathrm{RR}=0.84[0.67 \pm 1.04], \mathrm{p}=0.109)$.

\section{Discussion of Factors Associated with Treatment Effec- tiveness}

The other objective of this study was to identify factors associated with the effectiveness of injectable artesunate vis-à-vis quinine in patients with severe malaria supported in Kenge Reference General Hospital (HGRCCK). The results indicate that regardless of the regimen to which they were subjected (Quinine Artesunate or) patients still needed adjuvant treatment to improve their health, and that depending on the health status of everyone. For example, the addition of either the antipyretic or antibiotic or blood transfusion may be necessary in order to increase the therapeutic efficacy. Other patients still needed for the association of the Antipyretic antibiotics and blood transfusion, or antipyretic-antibiotic combination or Antipyretic transfusion. These relationships were statistically significant at 95\% confidence level (Chi-square $=9.50, \mathrm{df}=$ $4, p=0.05$ ). Hiens et al. [17] found similar results in their study of the treatment of severe malaria in children under 59 months. His results show that all the children who were subject to quinine or artesunate associated with antibiotics were given a speedy recovery. also observed that the need for blood transfusion during severe malaria is not exceptional. French on a recently published series of 400 patients with severe malaria, all treated with quinine, 114 patients were transfused (28.5\%) before being cured [18-20].

\section{Conclusion}

At present, the malaria resistance thresholds in several major antimalarials (quinine, amodiaquine, artemisinin, mefloquine, lumefantrine) still remain to be defined. The recommendations of WHO (2014) on the introduction of injectable artesunate molecule in the first line treatment of severe malaria instead of quinine infusion was widely followed. The question is whether this regimen can be considered effective after a consistent evaluation of different parameters leading to such efficiency. This study had to compare the efficacy of injectable artemisinin than quinine in the treatment of severe malaria in children under 5 years to identify factors associated with effectiveness. From the above, we can confirm that artesunate is more effective than quinine. The healing gain obtained with artesunate was $5.2 \%$ and the risk of death in a treatment quinine was 6.8\% higher. Moreover, the hospital stay is shorter with artesunate rather than quinine. The study also demonstrated that the addition of a drug (antipyretic or antibiotic or blood transfusion) would improve patient health. These results are consistent with several studies previously conducted in Africa, America, Asia and Europe available in the review of the international literature.

\section{References}

1. Nganga PN, Jayasinghe, G Kimani V, Shililu J, Kabutha C, et al. (2009) Bed net use and associated factors in a rice farming community in Central Kenya. Malaria Journal 8: 64-78.

2. Camara F (2011) Evaluation of the use of Insecticide Treated Nets to Long Term Action (LLINs) in the health district of Kissidougou Guinea Republic. Conakry Republic of Guinea.

3. (2014) WHO, World Health Organization? Support malaria, guidetraining module involved in the fight against malaria. Geneva: World Health Organization.

4. (2016) MOH, Ministry of Santee NHIS Reports 2016 Kenge: Provincial Health Division Kwango (DPS / Kwango) DRC.

5. Ouattara B (2007) Support for cerebral malaria in children aged 0-15 years in Nianankoro Fomba hospital Segou (UFH / S). Doctoral thesis Bamako: University of Bamako, Republic of Mali.

6. White N (2014) Third wave of resistance to antimalarial drugs in Thailand-Cambodia border. Phnom Penh Cambodia.

7. (2006) WHO, World Health Organization? Guidelines for the treatment of malaria. Geneva: WHO Secretariat.

8. Fargiere JJ Louis FJ, Duparcc S, Hounsinopu C, Ringwald OP, Danis M, et al. (1999) comparative trial of artemether and quinine in severe falciparum malaria in adults and older children in Cameroon Tropical Medicine 59(2): 151-156.

9. Miller LG, Panosian CB (1997) Ataxia and slurred speech after-artesunate treatment for falciparum malaria. N Engl J Med 336: 1328-1336.

10. Jauréguiberry S (2012) Treatment with intravenous artesunate in France. Letter to Infectiologist Volume XXVII - No. 6.

11. Dondorp N (2005) South-East Asian Quinine Artesunate Malaria-Trial (SEAQUAMAT) group. Artesunate versus quinine for Treatment of severe falciparum malaria: a randomized trial. Lancet 366(9487): 717-725.

12. (2013) High Public Health Council, Place of injectable artesunate in the treatment of severe malaria in adults and children. Working Group Report 1 February 2013 Collection Notices and Reports.

13. Hiens K, Angbo MA, Dasse SR, Yeboah O, Nguessan K, et al. (2014) Haptoglobin in children with severe falciparum malaria: Relations with age, noisy crumb and hemoglobin. Journal of Applied Biosciences 76: 6425-6432.

14. Kissinger E Tran, HT Hung NT, Farrar JJ (2000) Clinical and neurophysiological study of the effects of multiple doses of artemisinin is brain-stem function in Vietnamese patients. Am J Trop Med Hyg 63: 48-63.

15. Kreeftmeijer-Vegter AR, van Genderen PJ, Visser LG, Bierman, WF Clerinx, et al. (2012) Treatment outcome of intravenous artesunate in patients with severe malaria in the Netherlands and Belgium. Malaria Journal 11: 102-111.

16. Nei U (2011) From branch to bedside: You Youyou is Awarded the 2011 Lasker-DeBakey Clinical Medical Research Award for discovering artemisinin as a treatment for malaria. J Clin Invest 121(10): 3768-3773.

17. (2010) WHO, World Health Organization? Guidelines for the Treatment of Malaria, 1st edition, Geneva: World Health Organization.

18. (2011) WHO World Health Organization Guidelines, for the treatment of malaria, 2nd edition, Geneva: World Health Organization.

19. Phuong CXT, Bethell, DB Phuong, P, Tran TT Thuy TT, Thanh Ha NT, et al. (1997) Comparison of artemisinin suppositories, intramuscular artesunate and intravenous quinine for the treatment of severe childhood malaria. Trans R Soc Too much Med Hyg 91 (3): 335-342.

20. Udomsangpetch R, Pipitaporn B, Krishna S, White NJ (1996) Antimalarial drugs Reduce cyto-adherence and resetting of plasmodium falciparum. The Journal of Infectious Diseases 173 (3): 691-698. 


\section{ISSN: 2574-1241}

DOI: 10.26717/BJSTR.2019.18.003155

Prisca Nsimba Mayamba. Biomed J Sci \& Tech Res

CC (i) This work is licensed under Creative

Submission Link: https://biomedres.us/submit-manuscript.php

$\begin{array}{ll}\text { BIOMEDICAL } & \text { Assets of Publishing with us } \\ \text { RESEARCHES } & \text { Global archiving of articles } \\ & \text { - Immediate, unrestricted online access } \\ & \text { - Rigorous Peer Review Process } \\ \end{array}$

